\title{
Effects of Fertilization Treatments on the Growth Characteristics of Crataesus pinnatifida in a Container
}

\author{
Su-Jin Kim, Seak-Jin Kim, Sang-Kyun Han, Kyoung-Min Lee, and Young-Hyoo Kwon* \\ Department of Forestry \& Landscape Architecture, Korea National College of Agriculture and Fisheries, JeonJu 560-500, South Korea
}

\begin{abstract}
With increasing the demand of urban greenery, market of landscape trees using container has grown steadily. However, there has been little research on the proper fertilizer application for various landscape trees using container. This study was conducted to investigate optimal fertilizer intensity for Crataegus pinnatifida to produce landscape trees using container. The main objective of this study was to examine effects of fertilization treatments (Con., $0.5,1.0,2.0 \mathrm{~g} / \mathrm{L}$ ) on the growth characteristics of Crataegus pinnatifida. In this study, Crataegus pinnatifida showed the highest growth of tree height (TH), root collar diameter (RCD), dry biomass weight (DBW) and Seedling Quality Index (SQI) in $1.0 \mathrm{~g} \cdot \mathrm{L}^{-1}$ treatment $(p<.05)$. Especially, $1.0 \mathrm{~g} \cdot \mathrm{L}^{-1}$ treatment showed 4 to 9 times better quality than other treatments in SQI. In the case of height/root collar diameter (H/D) ratio and top/root (T/R) ratio, there were no significant differences between the treatments $(p>.05)$. Soil-plant analysis development (SPAD) value on $2.0 \mathrm{~g} \cdot \mathrm{L}^{-1}$ treatment was much higher than that on other treatments $(p<.05)$, but $2.0 \mathrm{~g} \cdot \mathrm{L}^{-1}$ treatment showed lower value than $1.0 \mathrm{~g} \cdot \mathrm{L}^{-1}$ treatment in the growth of TH, RCD, DBW and SQI. Therefore, our results support that $1.0 \mathrm{~g} \cdot \mathrm{L}^{-1}$ could be more economical and environmental than $2.0 \mathrm{~g} \cdot \mathrm{L}^{-1}$, which is the highest fertilizer intensity on Crataegus pinnatifida's container production.
\end{abstract}

Key words: $H / D$ ratio, SPAD value, SQI, T/R ratio

\section{I . Introduction}

The importance of urban greening is rising gradually due to industrialization and urbanization and the demand for landscape plants is increasing amid growing interest in urban greening. Among such landscape plants, landscape trees accounted for 676.9 billion KRW which was approximately $92 \%$ of 736 billion KRW for the total production amount of landscape construction materials as of 2015 (KFS, 2016), and the domestic output of landscape plants has increased by approximately $66.5 \%$ for the last 10 years from approximately 47.13 million trees in 2005 to approximately 78.46 million trees in 2015 (KFS, 2006; KFS 2016). Due to an increasing demand of landscape trees, the production technology enabling timely mass production and management and the standardization for efficient distribution and field application are required (Kwon

Received on May 25, 2017. Revised on June 13, 2017.

Accepted on June 15, 2017.

*Comesponding author: kwonla@korea.kr

This study was carried out with the support of the Rural Development Administration's joint research project (Research Project No. PJ010190). et al., 2016).

Meanwhile, trees grown in a container can be planted without damage to the belowground, so it is possible to reduce the defect rate due to less seasonal restrictions, produce standard seedlings (Cho, 2014), and save tree digging costs significantly. For these reasons, this is being researched as an alternative plan for stable supply of landscape trees. For studies regarding the container nursery of landscape tree, Kim and Kim (1999) carried out a study comparing the production cost according to the container production method and openground production method, and Park (1999), Kang (2008), Kim and Kim (2000), Lee (2002) and Yoon and Hong (2002) carried out studies regarding the material or size of container and growth. Cho (2014) also researched differences in the growth according to the nursery methods including the ground surface, aboveground, semiunderground and underground nursery methods. However, domestic studies on container nursery have relatively short history in comparison to the container nursery technologies in advanced countries (Son, 2013), and there is a lack of studies regarding a proper amount of fertilizer for each tree species that can be actually applied in container 
nursery.

A proper amount of fertilizer directly affects the growth of tree (Kimmins, 1997), and if proper fertilization treatment is not made in case of container nursery, the deterioration of seedling quality due to insufficient amount of fertilizer and environmental pollution problems due to leachate may occur (Hwang et al., 2013). The response to fertilization treatments varies with species, and it is significantly influenced by the level of fertilization treatments (Kwon and Lee, 1994; Hwang et al., 2003; Sung et al., 2011). Studies about the fertilization treatments of trees have been carried out by Kwon et al. (2009), Cho et al. (2011) and Han et al. (2016) but these studies mainly focused on container seedlings based on the container nursery system.

In this experiment, the growth characteristics of Crataegus pinnatifida which was known to have landscape value (Kang et al., 2002) and frequently used for urban greening were investigated with different fertilization level for stable supply of mature landscape trees for urban greening using Multifeed-20 (N:P:K=20:20:20), one of composite fertilizers. The result of this study can provide information regarding a proper amount of fertilizer required for growing Crataegus pinnatifida in a container including efficient amount of fertilizer for maximum growth, and environmental and economic feasibility of fertilization treatment. It also can be utilized as preliminary data for standardized quality management of landscape tree.

\section{Research method}

\section{Testing materials}

The experimental field plot $(22 \mathrm{~m} \times 7 \mathrm{~m})$ was installed on the experimental site of Korea National College of Agriculture and Fisheries located in Wansan-gu, Jeonju, Jeollabuk-do, and the experimental site was mulched with anti-weed sheet. 3-years-old Crataegus pinnatifida purchased from Seolim
Gardening, Seeds \& Seedlings was used as the testing plant All the trees were trimmed at the same tree height. The container was filled with perlite, peat moss and vermiculite mixed in the ratio of $1: 1: 1(\mathrm{v} / \mathrm{v})($ Table 1$)$ and trees were planted in April 13, 2015. One tree unit planted in a container was arranged at intervals of $1 \mathrm{~m}$ repeatedly for 5 times by treatment (Fig. 1), The drip irrigation watering system (Aqua Pro, 2014, Netafim Ltd., Israel) was installed for watering and the drip irrigation for $550 \mathrm{ml}$ was carried out once at AM 7:30 every day. The specifications of the containers (CH-10) used were $45.0 \mathrm{~cm}$ and $37.7 \mathrm{~cm}$ for the diameter at the top and bottom respectively, $30.2 \mathrm{~cm}$ for height and $36 \mathrm{~L}$ for the capacity.

\section{Fertilization treatment}

The fertilization treatment was carried out using Multifeed20 (N:P:K = 20:20:20, Haifa Chemicals, Israel) from May 2015 to September 2015 and from March 2016 to June 2016 when trees showed normal physiologic status after planting. Multifeed-20 used for the fertilization treatment is a watersoluble fertilizer consisting of $20 \% \mathrm{~N}-\mathrm{Total}, 20 \% \mathrm{P}_{2} \mathrm{O}_{2}, 20 \%$ $\mathrm{K}_{2} \mathrm{O}$ and various microelements including $\mathrm{B}, \mathrm{Cu}, \mathrm{Fe}, \mathrm{Mn}, \mathrm{Mo}$ and $\mathrm{Zn}$. The treatments were classified into three fertilization treatments and one control treatment (no fertilization), and the

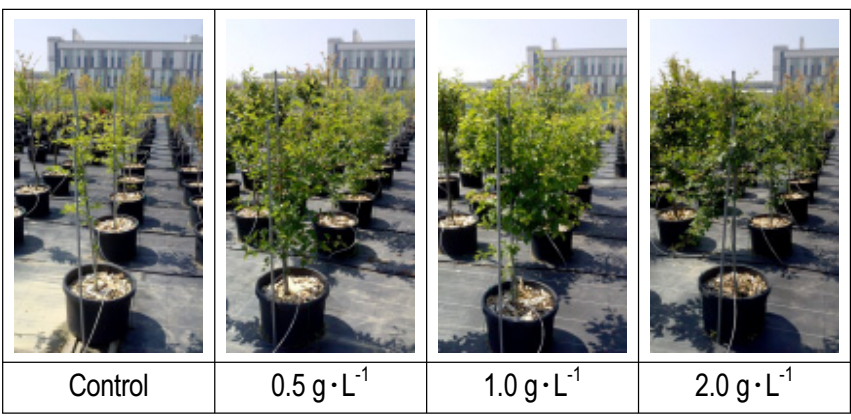

Fig. 1. Crataegus pinnatifida according to growth stage by different fertilization treatment.

Table 1. Media kinds used in this experiment.

\begin{tabular}{lcccc}
\hline \multicolumn{1}{c}{ Media kinds } & Soil texture $(\%)$ & Size $(\mathrm{mm})$ & Name of product & Producing company \\
\hline Perlite & 33.3 & $2-5$ & New-fullshine No-2 (100 L) & Green Fire Chemicals Ltd. \\
Peatmoss & 33.3 & $1-1.2$ & Baltisches substrat (150 L) & HAWITA-Gruppe GmbH \\
Vermiculite & 33.3 & $2-3$ & Beaminuri (100 L) & Green Fire Chemicals Ltd. \\
\hline
\end{tabular}


fertilization treatments including $0 \mathrm{~g} \cdot \mathrm{L}^{-1} 0.5 \mathrm{~g} \cdot \mathrm{L}^{-1}, 1.0 \mathrm{~g} \cdot \mathrm{L}^{-1}$ and $2.0 \mathrm{~g} \cdot \mathrm{L}^{-1}$ along with watering for $1 \mathrm{~L}$ were applied to each unit three times a week.

\section{Measurement and result analysis}

In order to investigate differences in the growth of Crataegus pinnatifida according to fertilization treatments, the tree height and root collar diameter were measured repeatedly using a folding rule and calipers for each treatment in early June, early October 2015 and early May, early June and early July 2016 and the growth amount and H/D ratio (height/root collar diameter) were calculated. After all experiments were finished in July 2016, the aboveground and belowground of the tree were dried in a dryer at the temperature of $70^{\circ} \mathrm{C}$ for 48 hours and the dry weight of each part was measured, and the T/R ratio was calculated based on the dry weight of each part. In addition the seedling quality index (SQI) was calculated using Dickson's quality index (Dickson et al., 1960) because it was difficult to determine the quality of seedling only with a single characteristic. The calculation formula is as follows.

$$
\text { SQI }=\text { Seedling dry weight }(\mathrm{g}) /(\mathrm{H} / \mathrm{D} \text { ratio }+\mathrm{T} / \mathrm{R} \text { ratio })
$$

Meanwhile, chlorophyll content was measured using SPAD502 (SPAD-502 Plus, Minolta, Japan) in order to investigate a difference in chlorophyll content according to the fertilization treatment. The SPAD value indicating chlorophyll content enables indirect measurement of chlorophyll content through the measurement of light transmittance from a leaf without destroying the leaf (Le Bail et al., 2005). The measurement was taken for 3 times at intervals of 30 days from May 2016 to July 2016. Eight leaves from each tree (two leaves in each of four directions including east, west, south and north) were selected and the SPAD value in the middle, top, bottom, left and right side (5 times) was measured from each leaf.

A difference between treatments was analyzed by carrying out the one-way ANOVA (SPSS ver. 21) for statistical analysis. A 95\% confidence interval was used in all statistical analyses, and Duncan's multiple range test was carried out for a treatment showing a significant difference after the one-way ANOVA and a difference between treatments was indicated.

\section{Results and discussions}

In order to confirm the growth of Crataegus pinnatifida according to the fertilization level, the growth amount was compared and evaluated by measuring the tree height and root collar diameter (Table 2). The tree height and root collar diameter growth amount of Crataegus pinnatifida were significantly different in four different fertilization treatment levels $(p<.05)$. And the fertilization treatments showed approximately $2 \sim 3$ times larger in tree height and root collar diameter growth amount compared to the control treatment. However, the aspect of growth amount increase varied by the fertilization treatment level, and $0.5 \mathrm{~g} \cdot \mathrm{L}^{-1}$ and $1.0 \mathrm{~g} \cdot \mathrm{L}^{-1}$ treatments with less amount of fertilizer showed the largest tree height growth amount than $2.0 \mathrm{~g} \cdot \mathrm{L}^{-1}$ treatments with the largest amount of fertilizer, and $1.0 \mathrm{~g} \cdot \mathrm{L}^{-1}$ treatment showed the largest root collar diameter growth.

Similarly, the dry weight of aboveground and belowground

Table 2. Growth characteristics of Crataegus pinnatifida by different fertilization treatment.

\begin{tabular}{|c|c|c|c|c|c|c|c|}
\hline $\begin{array}{l}\text { Fertilization } \\
\text { treatment } \\
\left(\mathrm{g} \cdot \mathrm{L}^{-1}\right)\end{array}$ & $\frac{\text { Height }}{\text { Growth }(\mathrm{cm})}$ & $\frac{\text { Root collar diameter }}{\text { Growth }(\mathrm{mm})}$ & \multicolumn{2}{|c|}{ Dry biomass weight (g) } & $\begin{array}{l}\mathrm{H} / \mathrm{D} \text { ratio } \\
\left(\mathrm{cm} \cdot \mathrm{mm}^{-1}\right)\end{array}$ & $\begin{array}{c}\mathrm{T} / \mathrm{R} \text { ratio } \\
\left(\mathrm{g} \cdot \mathrm{g}^{-1}\right)\end{array}$ & SQI \\
\hline Control & $24.8 \mathrm{c}^{\mathrm{z}}$ & $3.76 \mathrm{~b}$ & $44.72 \mathrm{~d}$ & $48.32 \mathrm{~d}$ & $9.20 \mathrm{a}$ & $0.99 \mathrm{~b}$ & $9.32 \mathrm{c}$ \\
\hline 0.5 & $76.0 \mathrm{a}$ & $8.43 \mathrm{a}$ & $299.82 \mathrm{~b}$ & $219.36 \mathrm{~b}$ & $9.21 \mathrm{a}$ & $1.38 \mathrm{ab}$ & $49.22 \mathrm{~b}$ \\
\hline 1.0 & $68.0 \mathrm{ab}$ & $10.72 \mathrm{a}$ & $421.48 \mathrm{a}$ & $280.46 \mathrm{a}$ & $7.47 \mathrm{a}$ & $1.49 \mathrm{a}$ & $80.02 \mathrm{a}$ \\
\hline 2.0 & $52.4 \mathrm{~b}$ & $9.87 \mathrm{a}$ & $205.32 \mathrm{c}$ & $142.48 \mathrm{c}$ & $7.47 \mathrm{a}$ & $1.54 \mathrm{a}$ & $40.24 \mathrm{~b}$ \\
\hline
\end{tabular}

H/D Ratio = Height/Root collar diameter ratio; T/R Ratio $=$ Top dry weight/Root dry weight ratio; SQI $=$ Seedling dry weight $(\mathrm{g}) /(\mathrm{H} / \mathrm{D}$ ratio $+\mathrm{T} / \mathrm{R}$ ratio $)$.

${ }^{\mathrm{z}}$ The same letter on the column for each media kinds is not significantly different based on Duncan's multiple range tests at the 0.05 levels. 
was higher in order of $1.0 \mathrm{~g} \cdot \mathrm{L}^{-1}>0.5 \mathrm{~g} \cdot \mathrm{L}^{-1}>2.0 \mathrm{~g} \cdot \mathrm{L}^{-1}>$ the control treatment $(p<0.05)$. In the result of Duncan's multiple range test, $1.0 \mathrm{~g} \cdot \mathrm{L}^{-1}$ treatment showed the highest dry weight. This result is similar to the result of studies conducted by Kwon et al. (2009) and Cho et al. (2011), and excessive amount of fertilizer deteriorated the growth.

There is no significant difference in the $\mathrm{H} / \mathrm{D}$ ratio between treatment levels $(p>.05)$, but $1.0 \mathrm{~g} \cdot \mathrm{L}^{-1}$ treatment and $2.0 \mathrm{~g} \cdot \mathrm{L}^{-1}$ treatment showed a relatively low $\mathrm{H} / \mathrm{D}$ ratio. $\mathrm{H} / \mathrm{D}$ ratio enables the judgment of healthiness of tree (Cho et al., 2011), and it is known that a high H/D ratio means that the seedling is vulnerable to damages by exposure to wind, drought and frost (Roller, 1977). Therefore, $1.0 \mathrm{~g} \cdot \mathrm{L}^{-1}$ treatment and $2.0 \mathrm{~g} \cdot \mathrm{L}^{-1}$ treatment with lower $\mathrm{H} / \mathrm{D}$ ratio were relatively healthier than the control treatment and $0.5 \mathrm{~g} \cdot \mathrm{L}^{-1}$ treatment.

The T/R ratio calculated based on the dry weight of aboveground and belowground was higher in order of $2.0 \mathrm{~g} \cdot \mathrm{L}^{-1}>$ $1.0 \mathrm{~g} \cdot \mathrm{L}^{-1}>0.5 \mathrm{~g} \cdot \mathrm{L}^{-1}>$ the control treatment, but a quantitative difference was below $1 \mathrm{~g}$, indicating that there was no significant difference $(p>.05)$.

The fertilization treatments showed the higher seedling quality index (SQI) of Crataegus pinnatifida seedling compared to the control treatment $(p<.05)$, and as the result of Duncan's multiple range test, $1.0 \mathrm{~g} \cdot \mathrm{L}^{-1}$ showed the best traits, which was approximately 4 9 times higher in comparison to other treatments. This shows a similar trend with the result of growth characteristics such as growth amount and dry weight, and the seedling quality index was high due to low $\mathrm{H} / \mathrm{D}$ ratio and high dry weight (Bayala et al., 2009).

The growth of trees according to the nutrition composition in soil affects various physiological responses as well as the

Table 3. SPAD value of Crataegus pinnatifida by different fertilization treatment.

\begin{tabular}{lccc}
\hline $\begin{array}{c}\text { Fertilization } \\
\text { treatment } \\
\left(\mathrm{g} \cdot \mathrm{L}^{-1}\right)\end{array}$ & May. & Jun. & Jul. \\
\cline { 2 - 4 } Control & $16.64 \mathrm{c}^{\mathrm{z}}$ & $25.42 \mathrm{~d}$ & $23.74 \mathrm{c}$ \\
0.5 & $36.70 \mathrm{~b}$ & $51.20 \mathrm{~b}$ & $47.23 \mathrm{ab}$ \\
1.0 & $33.87 \mathrm{~b}$ & $46.33 \mathrm{c}$ & $45.36 \mathrm{~b}$ \\
2.0 & $45.51 \mathrm{a}$ & $60.74 \mathrm{a}$ & $49.09 \mathrm{a}$ \\
$p$-value & .000 & .000 & .000 \\
\hline
\end{tabular}

${ }^{\mathrm{z}}$ The same letter on the column for each media kinds is not significantly different based on Duncan's multiple range tests at the 0.05 levels. growth amount and biomass of seedling, but it also affects photosynthesis, which is the final metabolite eventually (Lee et al., 2006). Meanwhile, chlorophyll content which is closely related to the rate of photosynthesis is also related to nitrogen content, so SPAD value which indicates nitrogen content indirectly is also presented as chlorophyll content (Loh et al., 2002; Yoon et al., 2005; Lee, 2007). In this experiment, the trend of chlorophyll content which was closely related to the rate of photosynthesis was measured at intervals of 30 days by the fertilization level for each period including early stage, middle stage and late stage (Table 3 ). As the experiment result, a statistically significant difference was shown in the SPAD value according to 4 fertilization treatment levels for all periods $(p<.05)$, and as a result of Duncan's multiple range test, $2.0 \mathrm{~g} \cdot \mathrm{L}^{-1}$ treatment showd the highest SPAD value (Fig. 2). This shows a similar trend with the result of study carried out by Kang et al. (2010), and as the amount of nitrogen fertilizer increased, the SPAD value which indicates the ratio of nitrogen content indirectly also has increased. However, when comparing the SPAD value measured from the fertilization treatments in this experiment with the SPAD value measured by Kang (2003) and Kang et al. (2010), it is considered that the SPAD value of all fertilization treatments except for the control treatment is relatively high. And, a difference in the SPAD value between fertilization treatments in the late stage was approximately below $2 \sim 4$, indicating that the actual effect on the rate of photosynthesis would be insignificant. Also, Piekielek et al. (1995) and Kim et al. (2005) reported that the SPAD value could be utilized as an indicator for nitrogen content rather than the relevance with growth characteristics. The reason that

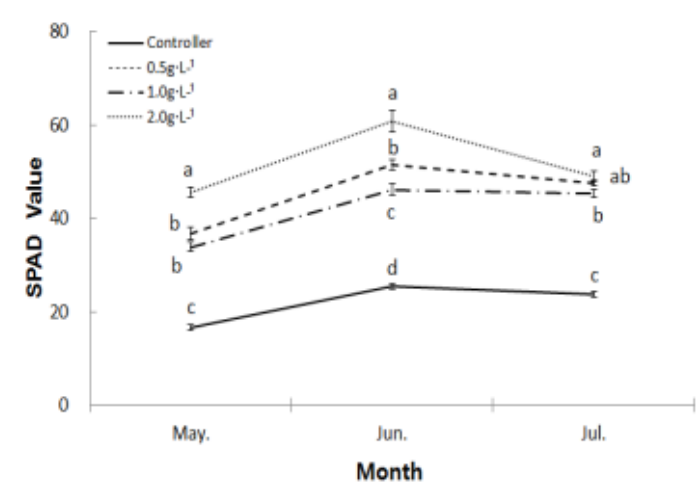

Fig. 2. Change of SPAD value according to growth stage by different fertilization treatment. 
$2.0 \mathrm{~g} \cdot \mathrm{L}^{-1}$ treatment with the largest amount of nitrogen fertilizer showed a higher SPAD value but relatively lower growth, seedling healthiness and quality index than $1.0 \mathrm{~g} \cdot \mathrm{L}^{-1}$ treatment with a half the amount of fertilizer would be deteriorated growth due to excessive nitrogen. A proper amount of nitrogen can promote the growth of tree but an excessive amount of nitrogen may cause deteriorated growth, environmental pollution, disease and insect damage and storm and flood damage (Kim et al., 2006).

In summary, the treatment showing the maximum growth effect in comparison to the minimum amount of fertilizer for the growth of Crataegus pinnatifida in a container is $1.0 \mathrm{~g} \cdot \mathrm{L}^{-1}$, and this is a proper amount of fertilizer by considering the environment and economic feasibility. In this way, the fertilization level is not always proportional to the growth, and the management and field application for mass production of landscape trees require a proper fertilization treatment for each type of tree. In addition, a study regarding proper container nursery system for landscape trees including proper soil, watering system and container is also required.

\section{Conclusions}

A proper nursery system for each tree such as soil, nutrition and watering system is required for efficient production of landscape trees growing in a container used for urban greening and gardening. In this experiment, the growth characteristics of Crataegus pinnatifida including growth amount, biomass, seedling healthiness (H/D ratio), T/R ratio, seedling quality index (SQI) and chlorophyll content (SPAD Value) with four fertilization treatment levels $(0,0.5,1.0,2.0 \mathrm{~g} / \mathrm{L})$ was investigated and analyzed to find the economical, eco-friendly and proper amount of fertilizer that could show the maximum growth effect in comparison to the minimum amount of fertilizer.

There were significant differences in the tree height and root collar diameter growth amount, dry weight of aboveground and belowground of Crataegus pinnatifida according to the fertilization treatment level. $1.0 \mathrm{~g} \cdot \mathrm{L}^{-1}$ treatment showed an excellent result. In the case of height/root collar diameter $(\mathrm{H} / \mathrm{D})$ ratio and top/root $(\mathrm{T} / \mathrm{R})$ ratio, there were no significant differences between the treatments.

The SQI of Crataegus pinnatifida was significantly different in four different fertilization treatment levels, and $1.0 \mathrm{~g} \cdot \mathrm{L}^{-1}$ treatment showed approximately $4 \sim 9$ times better traits than other treatments. The SPAD value was measured for each period including early stage, middle stage and late stage, and there was a significant difference in the SPAD value in all periods according to the fertilization level. $2.0 \mathrm{~g} \cdot \mathrm{L}^{-1}$ treatment showed the highest SPAD value. However, $2.0 \mathrm{~g} \cdot \mathrm{L}^{-1}$ treatment showed more poor tree growth and seedling quality index than $1.0 \mathrm{~g} \cdot \mathrm{L}^{-1}$ treatment, which contained a half the amount of fertilizer, indicating that excessive amount of nitrogen fertilizer was supplied, deteriorating the growth of trees.

To sum up the result of this experiment, a difference in the growth according to the fertilization level was confirmed from growing Crataegus pinnatifida in a container, and $1.0 \mathrm{~g} \cdot \mathrm{L}^{-1}$ treatment showed the best growth in comparison to the treatment with the largest amount of fertilizer. Therefore, $1.0 \mathrm{~g} \cdot \mathrm{L}^{-1}$ treatment showed the maximum growth effect in comparison to the minimum amount of fertilizer, and this is a proper amount of fertilizer by considering the environment and economic feasibility.

\section{References}

Bayala, J., M. Dianda, J. Wilson, S.J. Ouedraogo, and K. Sanon. 2009. Predicting field performance of five irrigated tree species using seedling quality assessment in Burkina Faso, West Africa. New For. 38(3):309-322. DOI: 10.1007/s11056-009-9149-4

Cho, M.S., S.W. Lee, J.H. Bae, and G.S. Park. 2011. Effect of different fertilization on physiological characteristics and growth performances of Eucalyptus pellita and Acacia mangium in a container nursery system. J. Bio-Environ. Control 20(2):123-133.

Cho, Y.H. 2014. A comparison of the growth of woody landscape plants in cultivation method using container. MS thesis, Honam Univ., Gwangju, Korea.

Dickson, A., A.L. Leaf, and J.F. Hosner. 1960. Quality appraisal of white spruce and white pine seedlings stock in nurseries. For. Chron. 36(1):10-13. DOI: 10.5558/tfc36010-1

Han, S.H., J.K. Byun, M.S. Cho, J.Y. An, G.S. Park, S.B. Kim, and B.B. Park. 2016. The effects of 7 fertilizers on the growth and nutrient concentrations of Fraxinus rhynchophylla, Fraxinus mandshurica, Pinus koraiensis, and Abies holophylla seedlings. J. Korean For. Soc. 105(2):177-185. DOI: 10.14578/jkfs.2016. 105.2.177

Hwang, J.H., M.S. Cho, A.R. Yang, and S.K. Kim. 2013, April. Effects 
of fertilization on the physiological characteristics and growth performances of container seedlings of Torreya nucifera. Korean Inst. For. Recreat. Jeju, Korea.

Hwang, J.O., Y.H. Son, M.J. Yi, J.K. Byoung, J.H. Jung, and C.Y. Lee. 2003. Studies on relationship between composition and type of fertilizer and seedling (I. Influence on biomass, specific leaf area and chlorophyll content). For. Bioenergy 22(2):44-53.

Kang, H.C., K.K. Shim, Y.M. Ha, and W.H. Lee. 2002. New varieties with thornless branches of Crataegus pinnatifida Bunge. Korea J. Hort. Sci. Technol. 20(3):252-256.

Kang, S.B., I.B. Lee, T.J. Lim, and J.M. Park. 2010. Effect of nitrogen fertigation by soil testing on the growth and yield of 'Campbell Early' (Vitis labrusca L.) grapevine in field cultivation. Korean J. Environ. Agric. 28(4):12-19.

Kang, T.H. 2008. Study on a tree production technique that used by container. MS thesis, Pusan National Univ., Pusan, Korea.

Kang, Y.G. 2003. Influence of nitrogen application rate on growth and dry matter yield of Achyranthes japonica Nakai. Korean J. Med. Crop Sci. 11(2):109-114.

KFS (Korea Forest Service). 2006. Statistical yearbook of forestry. Korea Forest Service, Daejeon, Korea. Retrieved from http:// www.forest.go.kr/

KFS (Korea Forest Service). 2016. Statistical yearbook of forestry. Korea Forest Service, Daejeon, Korea. Retrieved from http:// www.forest.go.kr/

Kim, D.U. and M.S. Kim. 2000. Effects of root restriction by clay pot and root control bag on growth of Acer palmatum. J. Korean Inst. Landsc. Archit. 28(4):1-8.

Kim, M.H., J.C. Shin, and B.W. Lee. 2005. Applicability of vagetation index and SPAD reading to nondestructive diagnosis of rice growth and nitrogen nutrition status. Korean J. Crop Sci. 50(6): 369-377.

Kim, M.H., J.D. Fu, and B.W. Lee. 2006. Determining nitrogen topdressing rate at panicle initiation stage of rice based on vegetation index and SPAD reading. Korean J. Crop Sci. 51(5): 386-395.

Kim, T.J. and H.B. Kim. 1999. Study on the container versus traditional landscape tree production methods: Economic feasibility study. Collect. Diss. 31:171-178. Retrieved from http://www.riss.kr/ link?id=A30032394

Kimmins, J.P. 1997. Forest ecology: a foundation for sustainable management. 2th ed. New Jersey, USA: Prentice Hall, Inc.

Kwon, K.W. and J.H. Lee. 1994. Growth performances and physiological responses of Quercus spp. and Fraxinus rhynchophylla subjeted to different soil moisture regimes and nutrition levels. J. Korean For. Soc. 83(2):164-174.

Kwon, K.W., M.S. Cho, G.N. Kim, S.W. Lee, and K.H. Jang. 2009. Photosynthetic characteristics and growth perfomances of con- tainerized seedling and bare root seedling of Quercus acutissima growing at different fertilizing schemes. J. Korean For. Soc. 98(3): 331-338.

Kwon, Y.H., S.J. Kim, H.K. Oh, S.K. Han, and S.J. Kim. 2016. Effects of media kinds and container forms for urban agriculture on the growth characteristics of several herbaceous and woody plants. J. Korean Soc. People Plants Environ. 19(5):477-486. DOI: 10.11628/ ksppe.2016.19.5.477

Le Bail, M., M.H. Jeuffroy, C. Bouchard, and A. Barbottin. 2005. Is it possible to forecast the grain quality and yield of different varieties of winter wheat from Minolta SPAD meter measurements?. Eur. J. Agron. 23(4):379-391. DOI: 10.1016/j.eja.2005.02.003

Lee, C.Y. 2007. Characteristics of photosynthesis with growing stages by different shading materials in Panax ginseng C. A. Meyer. Korean. J. Med. Crop Sci. 15(4):276-284.

Lee, S.W., J.H. Choi, S.K. Yoo, S.K. Kim, J.H. Bae, and H.S. Kyo. 2006. Effect of raw material properties on growth characteristics of broad-leaved container seedlings. J. Bio-Environ. Control 15(3):244-249.

Lee. H.J. 2002. Studies on root development of root cutting seedlings of Aralia elata seemann grown in plastic netting container. MS thesis, Konkuk Univ., Chungju, Korea.

Loh, F.C., J.C. Grabosky, and N.L. Bassuk. 2002. Using the SPAD 502 meter to assess chlorophyll and nitrogen content of Benjamin fig and cotton wood leaves. HortTechnology 12(4):682-686.

Park, Y.J. 1999. Growth characteristics of landscape trees on the size of nonwoven fabric container. J. East Coast. Res. 10(2):49-63.

Piekielek, W.P., R.H. Fox, J.D. Toth, and K.E. Macneal. 1995. Use of a chlorophyll meter at early dent stage of corn to evaluate nitrogen sufficiency. Agron. J. 87(3):403-408. DOI: agronj1995. $00021962008700030003 x$

Roller, KJ. 1977. Suggested minimum standards for containerized seedlings in Nova Scotia (Information Report M-X-69). Canada: Canadian Forestry Service Publications. Retrieved from http:// www.cfs.nrcan.gc.ca/publications/?id=7692

Son, I.K. 2013. A study on the improvement scheme on tree production technology using containers. MS thesis, Kongju National Univ., Kongju, Korea.

Sung, H.I., K.S. Song, Y.G. Cha, and J.J. Kim. 2011. Characteristics of growth and seedling quality of 1-year-old container seedlings of Quercus myrsinaefolia by shading and fertilizing treatment. J. Korean For. Soc. 100(4):598-608.

Yoon, H.G., S.H. Oh, K.H. Kwon, J.T. Jang, and J.S. Seo. 2005, May. Effect of nitrogen concentration on fruit cracking in 'Kyoho' grape. Korean Soc. Hortic. Sci., Jeju, Korea.

Yoon, T.S. and S.G. Hong. 2002. Studies on production of plastic net container seedlings of Hovenia dulcis Thunb. J. Agric. Resour. Dev. 24:43-48. Retrieved from http://www.riss.kr/link?id=A19605854 